\title{
Impression technique for a complete-arch prosthesis with multiple implants using additive manufacturing technologies
}

Revilla-León, Marta ; Sánchez-Rubio, José Luis ; Oteo-Calatayud, Jesús ; Özcan, Mutlu

\begin{abstract}
This article describes an impression technique for a complete-arch prosthesis supported by multiple implants where additive manufacturing technologies were used to fabricate a splinting framework and a custom tray. The technique presented uses a shim method to control the homogenous splinting acrylic resin and impression material during the procedure, thereby reducing laboratory and chairside time and the number of impression copings and laboratory analogs needed.
\end{abstract}

DOI: https://doi.org/10.1016/j.prosdent.2016.08.036

Posted at the Zurich Open Repository and Archive, University of Zurich

ZORA URL: https://doi.org/10.5167/uzh-145971

Journal Article

Accepted Version

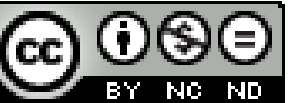

The following work is licensed under a Creative Commons: Attribution-NonCommercial-NoDerivatives 4.0 International (CC BY-NC-ND 4.0) License.

Originally published at:

Revilla-León, Marta; Sánchez-Rubio, José Luis; Oteo-Calatayud, Jesús; Özcan, Mutlu (2017). Impression technique for a complete-arch prosthesis with multiple implants using additive manufacturing technologies. Journal of Prosthetic Dentistry, 117(6):714-720.

DOI: https://doi.org/10.1016/j.prosdent.2016.08.036 
JPD-16-375

Impression technique for complete arch with multiple implants using additive manufacturing technologies

\begin{abstract}
This article describes an impression technique for a complete arch prosthesis supported by multiple implants where additive manufacturing technologies were used to fabricate a splinting framework and a custom tray. The presented technique uses a shim method, allowing the control of homogenous splinting acrylic resin and impression material during the procedure that could reduce laboratory and chairside time and the number of impression copings and laboratory analogs needed.
\end{abstract}

\title{
INTRODUCTION
}

When fabricating implant-supported fixed dental prostheses (FDPs), accurate reproduction of implant position on the definitive cast is essential. The definitive cast has to represent 3dimensional (3D) orientation of the implants in position. ${ }^{1}$ The precision of the definitive cast is essential for the fit of an implant-supported FDP requiring a precise impression technique to produce an accurate implant position on the definitive cast. ${ }^{2}$ The accuracy of impressions is affected by splinting impression copings, ${ }^{3}$ implant angulation,,${ }^{4,5}$ number of implants, ${ }^{3}$ polymerization shrinkage of the impression material, ${ }^{6-8}$ setting expansion of the dental stone, ${ }^{6-8}$ and the design and rigidity of the impression tray. ${ }^{6-8}$ Among all possible factors affecting the accuracy of impressions, splinting or not splinting seems to be the most significant ${ }^{3}$ especially when 4 or more implants are present in the dental arch. ${ }^{3,9}$ 
During splinting, distortion of the splint materials and/or fracture of the connection between the splint material and the impression copings, may affect the accuracy. ${ }^{10}$ Also, polymerization shrinkage of autopolymerizing acrylic resin at 24 hours, ranging between $7 \%$ and $9 \%$, where $80 \%$ of the shrinkage occurs within 17 minutes when materials were mixed at room temperature, yield to inaccuracy in the definitive impression. ${ }^{11}$

Additive manufacturing (AM) technologies have potential to substitute subtractive ones. $^{12}$ The ASTM International committee F42 on AM technologies has defined 7 categories: stereolithography (SLA), material jetting, material extrusion, binder jetting, powder bed fusion (PBF), sheet lamination, and direct energy deposition. ${ }^{13}$ Among these categories, direct metal laser sintering (DMLS) is a metal additive manufacturing technology that is based on a high powered laser beam focused onto a bed of powdered metal that fuse a thin solid layer. When a framework is fabricated through this route the unused remaining powder is filtered and used in the next batch. ${ }^{14,15}$ AM technologies use a design created in a 3D modelling software and digital light processing (DLP) technology in order to print the 3D object. ${ }^{16,17}$ In this technique, a vat of a liquid polymer is exposed to light from a DLP projector under light protected conditions. The DLP projector then displays the image of the 3D model onto the liquid polymer and the exposed liquid polymer sets. The process is repeated until the $3 \mathrm{D}$ model is complete and the vat is drained of liquid, revealing the solidified model.

Previous studies have demonstrated acceptable accuracy of the intraoral scanning devices ${ }^{18-22}$ but procedures requiring multiple steps can accumulate an error which could result in poor fit between the implants and the restorative components. ${ }^{23}$ Modified techniques for splitting implants in a complete arch implant impression procedure have been previously described. ${ }^{24,25}$ The present technical report describes an impression technique for complete arch containing 
multiple implants where additive manufacturing technologies were used in order to fabricate a splinting framework and a custom tray that reduces the handmade procedures.

\section{TECHNIQUE}

A patient with an edentulous maxilla having 6 implants (4 Tissue Level RN and 2 Tissue Level NNC; Straumann AG) was referred for a metal-acrylic resin implant-borne FDP. The technique below describes a situation where DMLS was used for the metal splinting structure and DLP for the custom tray fabrication:

1. Remove the healing abutments with a specific screw driver (Straumann screwdriver: Straumann AG) and irrigate the internal connection of each implant at the preliminary impression appointment. For conventional impression, secure the 6 open tray impression copings (Straumann AG) to the implants to a preload of $15 \mathrm{~N}$ with a torque wrench (Straumann AG). Make a preliminary irreversible impression using hydrocolloid impression material with a conventional metal impression tray. When the impression material is set, recover the impression and remove the impression copings (Fig. 1A). For digital impressions, secure the intraoral scan-bodies (Scan-bodies for RN Straumann implant; 3Shape). Make an intraoral digital impression with an intraoral scanning device (Trios; 3Shape) and remove the intraoral scan-bodies. Then, replace the healing abutments on each implant.

2. Transfer the data to the specific dental software to design the splinting structure and the custom tray. For the conventional impression, load a disposable syringe (Monoject 412 Syringe; Salvin Dental) with a thin mix of autopolymerizing acrylic resin (1-part polymer: 2parts monomer) (Pattern Resin; GC Corp) and inject the material into the impression coping 
sites inside the preliminary impression (Fig. 1B). After polymerization, pour the rest of the impression with die stone (Fujirock EP; GC Corp) at a ratio of $22 \mathrm{~mL}$ water to $110 \mathrm{~g}$ dental stone mixed under vacuum for 30 seconds. Recover the preliminary cast after dental stone is completely set (Fig. 1C). For intraoral digital impression, spray a thin homogenous layer of the specific scanning spray (Cerec Optispray; Dentsply Sirona) and use an optical laboratory scanner (3shape; 3Dental Dental Laboratory). Import the data from the digital impression to the software (3Shape) to obtain the digital preliminary cast.

3. Use the tools of the dental software to design the splinting framework (Fig. 2) from the digital cast. Leave a uniform space of $1.5 \mathrm{~mm}$ around each impression coping. Send the stereolithography (STL) file to the laboratory for the fabrication (EOS M270 printer; 3Dental Dental Laboratory) (Fig. 3).

4. Use the tools of the dental software to design the custom tray over the splinting structure (Fig. 4). Leave a uniform space of 2 to $3 \mathrm{~mm}$ for the impression material. Send the STL file to the laboratory for fabrication (Rapidshape D40; 3Dental Dental Laboratory) (Figs. 5).

5. Remove the healing abutments, irrigate the internal connection of each implant with chlorhexidine prior to definitive impression. Secure the impression copings with a preload of $15 \mathrm{~N}$ with a torque wrench (Fig. 6).

6. Evaluate the splinting structure and the custom tray in the patient's mouth.

7. Apply autopolymerizing resin (Pattern resin; GC Corp) around the impression copings with intraoral tips on the composite resin syringe. Pick up one impression coping at a time, and after acrylic resin is completely polymerized, continue with the subsequent copings (Fig. 7).

8. Evaluate the custom tray for border extension and mold the borders as in the conventional complete denture impression procedures (Fig. 8). Then, remove the tray, clean, dry, and coat 
adhesive (Impregum; 3M ESPE) on the internal surface of the tray and over the compound at the borders.

9. Dispense medium viscosity impression material (Impregum; 3M ESPE) into both the impression syringe and the custom tray. Inject the impression material underneath the splinting structure with a polyether syringe and seat the custom tray.

10. Recover the impression after the polyether impression material is completely set and pour the impression following the conventional procedures (Fig. 9).

\section{DISCUSSION}

The presented method describes an implant impression technique for a complete arch where AM technologies are employed to fabricate the custom tray and the metal splinting structure. The clinical procedures for the impression making is similar to previously described techniques. ${ }^{24}$ However, the application of AM technologies provide different advantages to the conventional procedures, namely handmade procedures are eliminated, homogeneous space for the splinting material between the impression abutments and the splinting structure is achieved, uniform space for the impression material between the splinting structure and the custom tray is controlled, and open custom tray around the impression abutments is maintained.

During the described technique and as an alternative of conventional procedures, an intraoral scanning device was employed in order to obtain the preliminary cast. The function of the preliminary cast model was to have a representation of the 3D implant position and replicate the surrounding buccal structures. Furthermore, the cast model would allow fabrication of the custom splinting structure and the open custom tray. 
Compared to methods where the custom tray and the splinting structure was fabricated using an analogue manual protocol, ${ }^{24,25}$ the technique described here using the additive manufacturing procedures could eliminate some of the laboratory work. Possible limiting factors such as implant angulation, inter-implant distance, open mouth limitations should be elaborated in future studies.

\section{SUMMARY}

The described impression technique uses additive manufacturing technologies to fabricate a splinting framework and a custom tray for complete arch containing multiple implants. 


\section{REFERENCES}

1. Waskewicz GA, Ostrowski JS, Parks VJ. Photoelastic analysis of stress distribution transmitted from a fixed prosthesis attached to osseointegrated implants. Int J Oral Maxillofac Implants 1994;9:405-11.

2. Ortop A, Jemt T, Bäck T, Jälevik T. Comparisons of precision of fit between cast and CNCmilled Titanium implant frameworks for the edentulous mandible. Int J Prosthodont 2003;16:194-200.

3. Lee H, So JS, Hochstedler JL, Ercoli C. The accuracy of implant impressions: a systematic review. J Prosthet Dent 2008;100:285-91.

4. Frieberg B, Jemt T, Lekholm U. Early failure in 4,641 consecutively placed Bränemark dental implants: A study from stage 1 surgery to the connection of completed prostheses. Int J Oral Maxillofac Implants 1991;6:142-6.

5. Jaffin R, Berman C. The excessive loss of Bränemark implants in type IV bone: A 5-year analysis. J Periodontol 1991;62:2-4.

6. Reisbeck MH, Matyas J. The accuracy of highly filled elastomeric impression materials. J Prosthet Dent 1975;33:67-72.

7. McCabe JF, Storer R. Elastomeric impression materials. The measurement of some properties relevant to clinical practice. Br Dent J 1980;73:73-9.

8. Ciesco JN, Malone WFP, Sandrik JL, Mazur B. Comparison of elastomeric impression materials used in fixed prosthodontics. J Prosthet Dent 1981;45:89-94.

9. Papaspyridakos P, Benic GI, Hogsett VL, White GS, Lal K, Gallucci GO. Accuracy of implant casts generated with splinted and nonsplinted impression techniques for edentulous patients: an optical scanning study. Clin Oral Impl Res 2012;23:676-81. 
10. Spector MR, Donovan TE, Nicholls JI. An evaluation of impression techniques for osseointegrated implants. J Prosthet Dent 1990;63:444-7.

11. Mojon P, Oberholzer JP, Meyer JM, Belser UC. Polymerization shrinkage of index and pattern acrylic resins. J Prosthet Dent 1990;64:684-8.

12. Alcisto J, Enriquez A, Garcia H, Hinkson S, Steelman T, Silverman E, Valdovino P, Gigerenzer H, Foyos J, Ogren J, Dorey J, Karg K, McDonald T, Es-Said S. Tensile properties and microstructures of laser-formed Ti-6Al-4V. J Mater Eng Perf 2011;20:203-12.

13. Muthu SS, Savalani MM (Eds.). Handbook of sustainability in additive manufacturing. Springer 2016. p. 9-12.

14. Deckard C, Beaman JJ. Process and control issues in selective laser sintering. Am Soc Mech Eng Prod Eng Div 1988;33:191-7.

15. Brown C. 3D Printing and Laser sintering technologies. Inside Dental technology, AEGIS Communications, 2011;2(7). http://www.dentalaegis/idt/2011/08/3d-printing-and-laser-sinteringtechnologies. Accessed 16 July 2016

16. Hornbeck LJ. Digital light processing and mems: timely convergence for a bright future. In Proceedings SPIE 1995;2639:2426.

17. Liu Q, Leu MC, Schmitt SM. Rapid prototyping in dentistry: technology and application. Int J Adv Manuf Technol 2006;29:317-35.

18. Joda T, Brägger U. Patient-centered outcomes comparing digital and conventional implant impression procedures: a randomized crossover trial. Clin Oral Impl Res 2015 [Epub ahead of print] 
19. Moreira AH, Rodrigues NF, Pinho ACM, Fonseca JC, Vilaça JL. Accuracy comparison of implant impression techniques: a systematic review. Clin Imp Dent and Relat Res 2015:17:e75164.

20. González de Villaumbrosia P, Martínez-Rus F, García-Orejas A, Salido MP, Pradíes G. In vitro comparison of the accuracy (trueness and precision) of six extraoral dental scanners with different scanning technologies. J Prosthet Dent 2016 [Epub ahead of print] 21. Jeong ID, Lee JJ, Jeon JH, Kim JH, Kim HY, Kim WC. Accuracy of complete-arch model using an intraoral video scanner: An in vitro study. J Prosthet Dent 2016;115:755-9.

22. Chochlidakis KM, Papaspyridakos P, Geminiani A, Chen CJ, Feng IJ, Ercoli C. Digital versus conventional impressions for fixed prosthodontics: A systematic review and metaanalysis. J Prosthet Dent 2016 [Epub ahead of print]

23. Tan KB. The clinical significance of distortion in implant prosthodontics: is there such a thing as passive fit? Ann Acad Med Singapore 1995;24:138-57.

24. Ma J, Rubenstein JE. Complete arch implant impression technique. J Prosthet Dent 2012;107:405-10.

25. Ma Bergin J, Rubenstein JE, Mancl L, Brudvik JS, Raigrodski AJ. An in vitro comparison of photogrammetric and conventional complete-arch implant impression techniques. J Prosthet Dent 2013;110:243-51. 


\section{FIGURES}

Fig. 1. A, Impression coping abutments placed in patient's mouth. B, Irreversible hydrocolloid impression. C, Pouring preliminary impression with acrylic resin for impression copings. D, Preliminary cast obtained by pouring irreversible hydrocolloid impression.

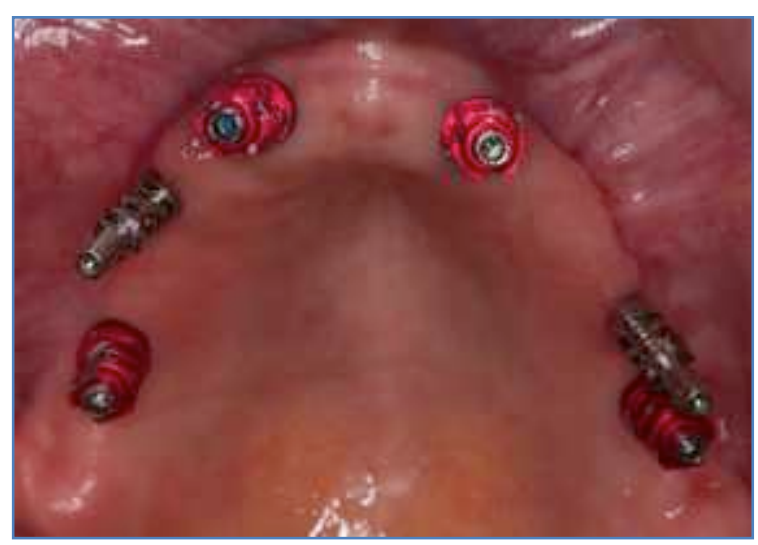

A)

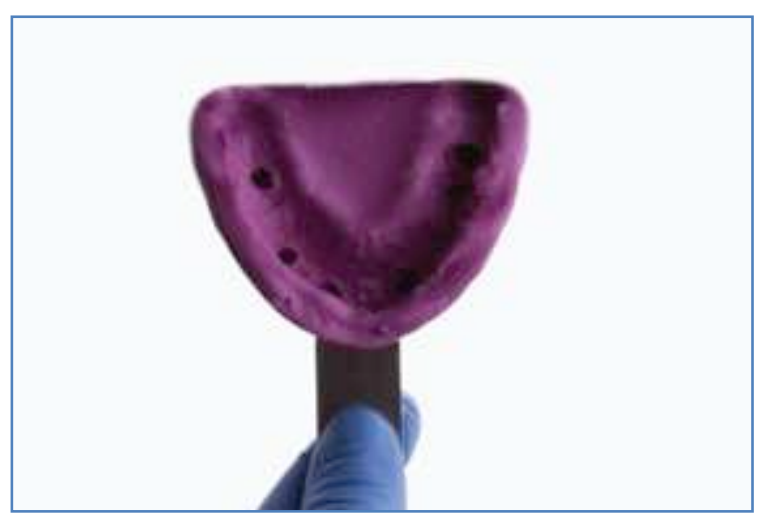

B)

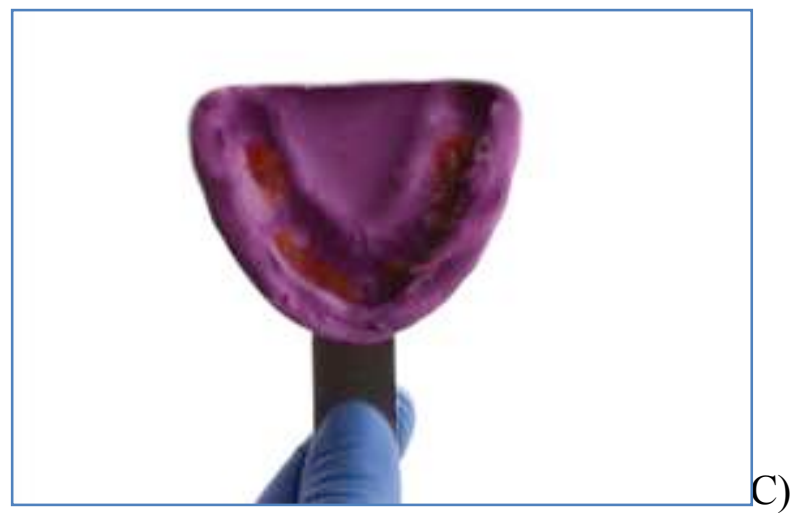




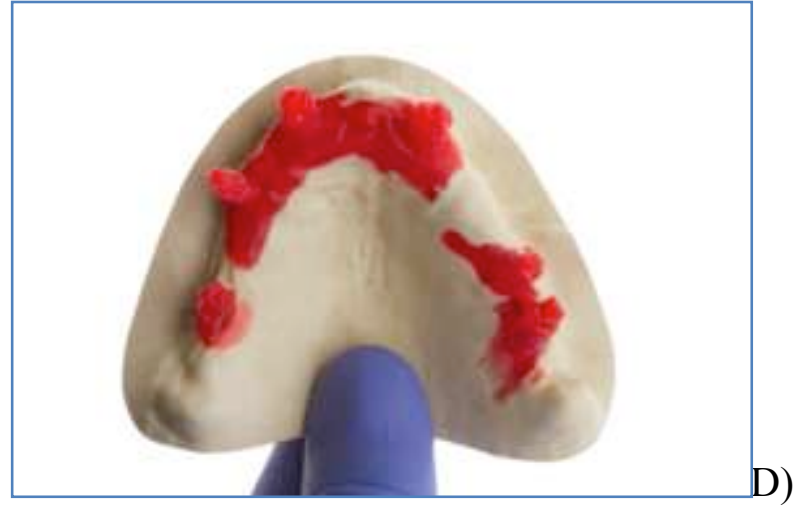

Figs. 2. A, Digital preliminary cast obtained by digital impression technique using an intraoral scanner, B, Digital design of splinting framework for the impression.
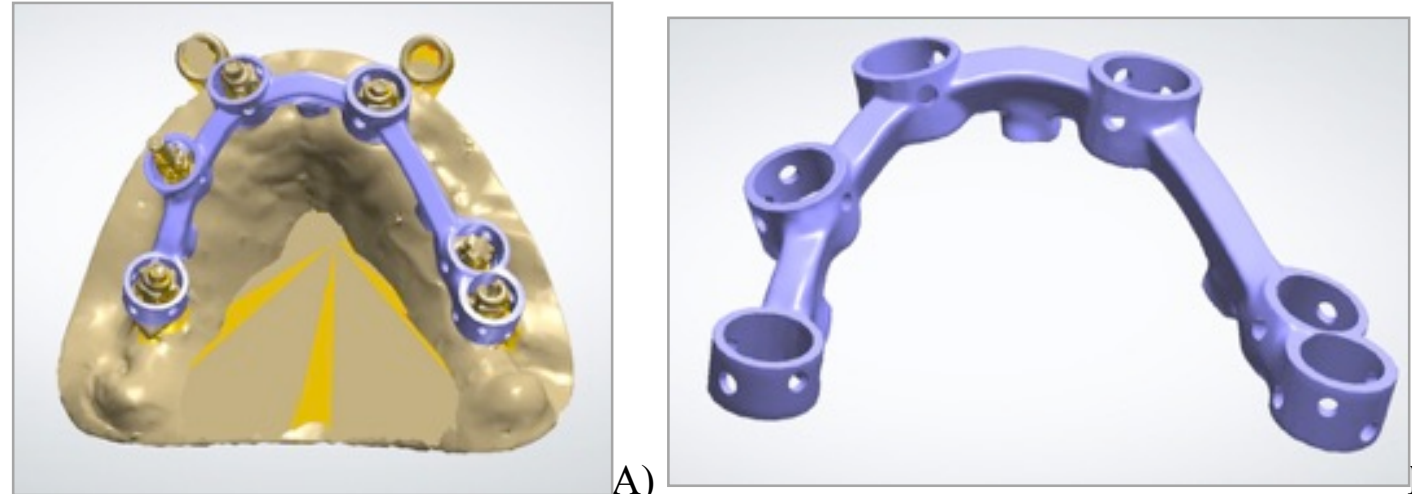

A)

B)

Fig. 3. Splinting framework produced through DMLS additive manufacturing technology.

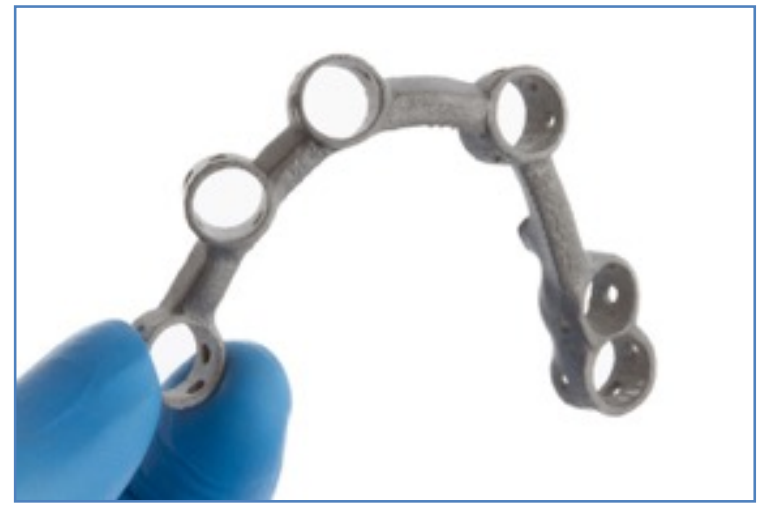


Fig. 4. A, Digital design of custom tray for impression on digital model and B, After removal from model.
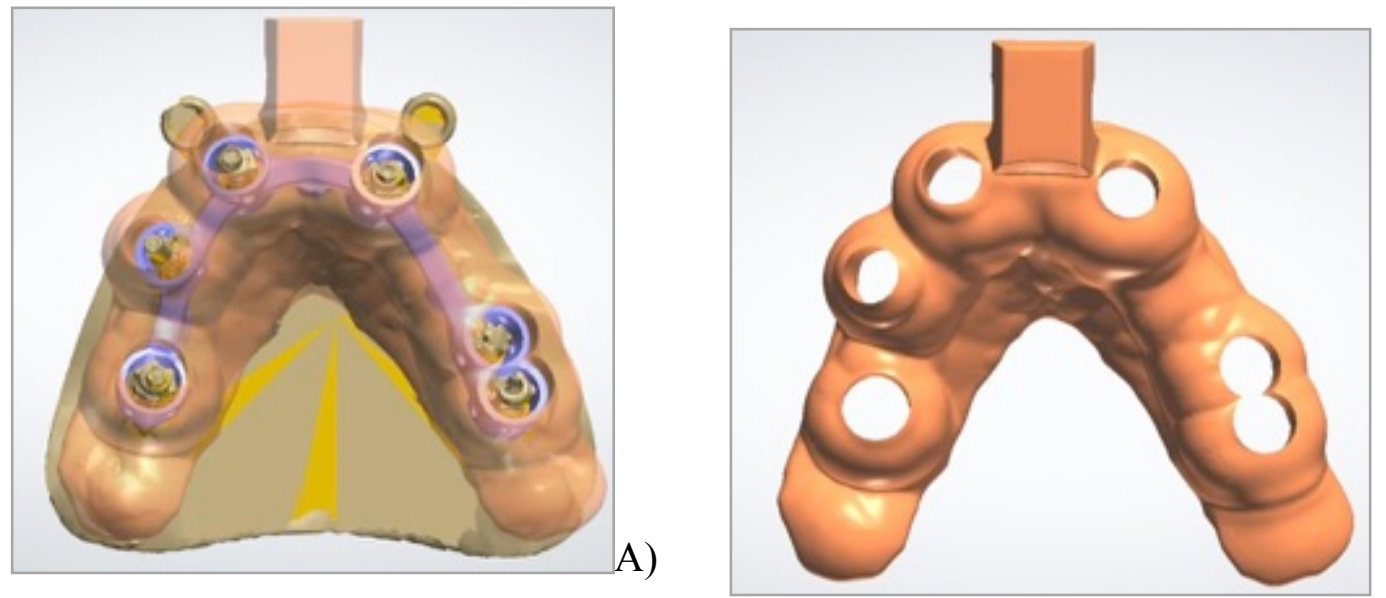

B)

Fig. 5. A, Custom tray produced through DLS additive manufacturing technology, B, Splinting framework positioned in custom tray.

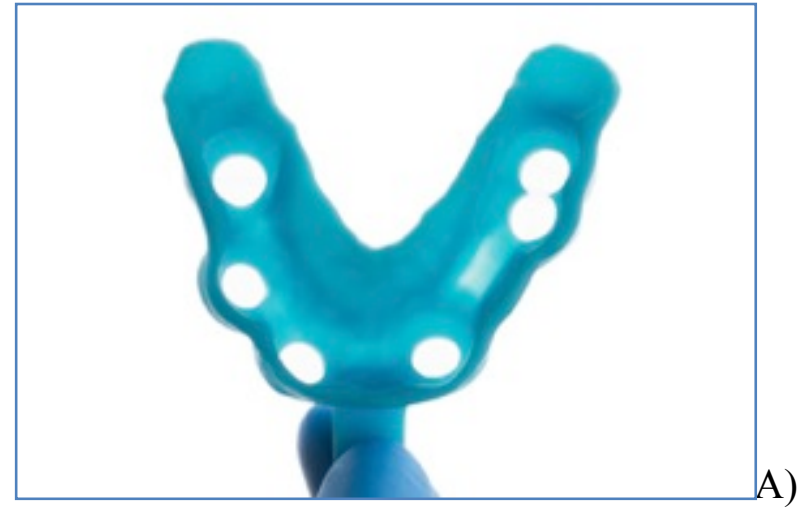




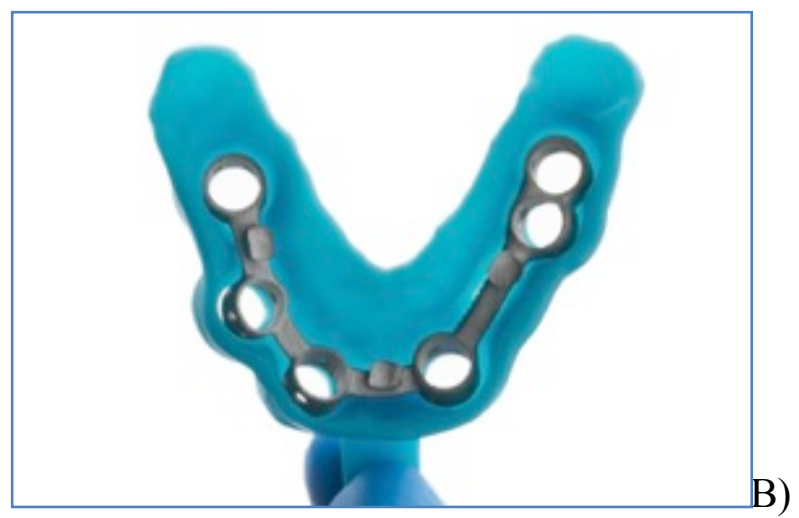

Fig. 6. Periapical radiographs showing complete seating of impression copings, on implant no. A, Maxillary right first molar and canine, B, Maxillary right central incisor, maxillary left central incisor, C, Maxillary left second premolar and first molar.
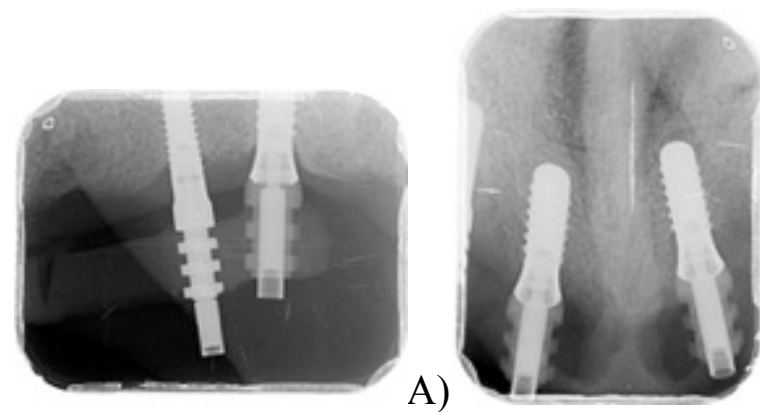

A)

B)

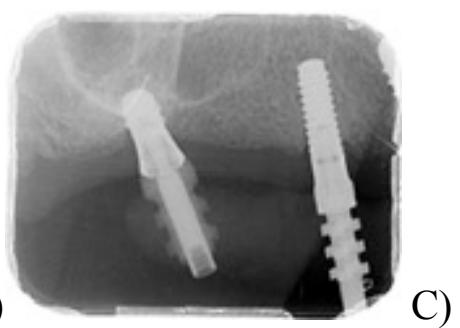

Fig. 7. A, Impression copings secured in 3D printed metal splinting framework, B, Application of auto-polymerizing acrylic resin around impression copings, C, Complete setting of acrylic resin before making polyether impression. 

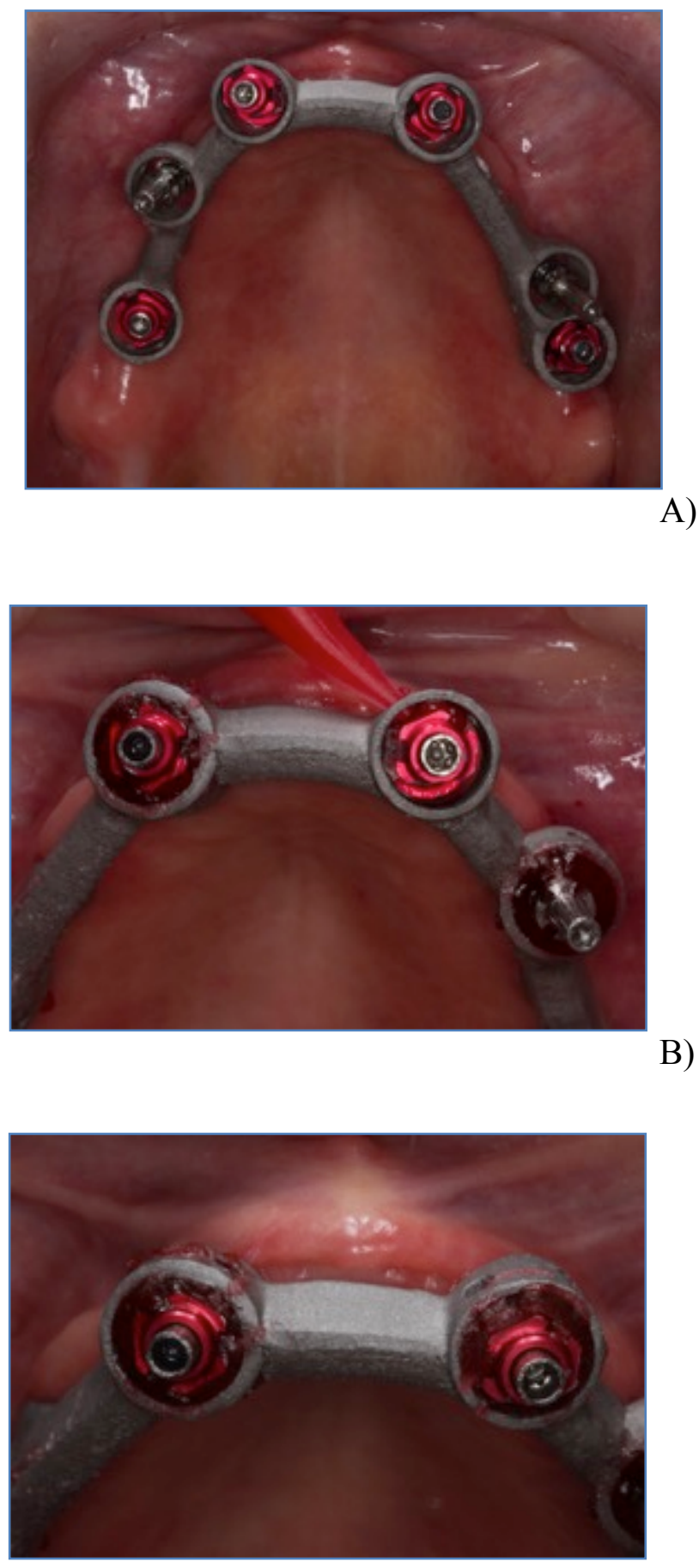

C) 
Fig. 8. Border moulding of custom tray.

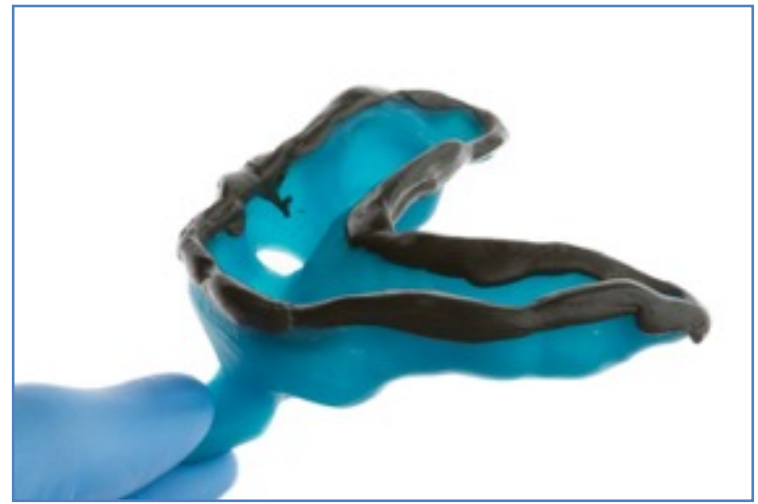

Fig. 9. A, Final impression with polyether impression material, B, Definitive cast.

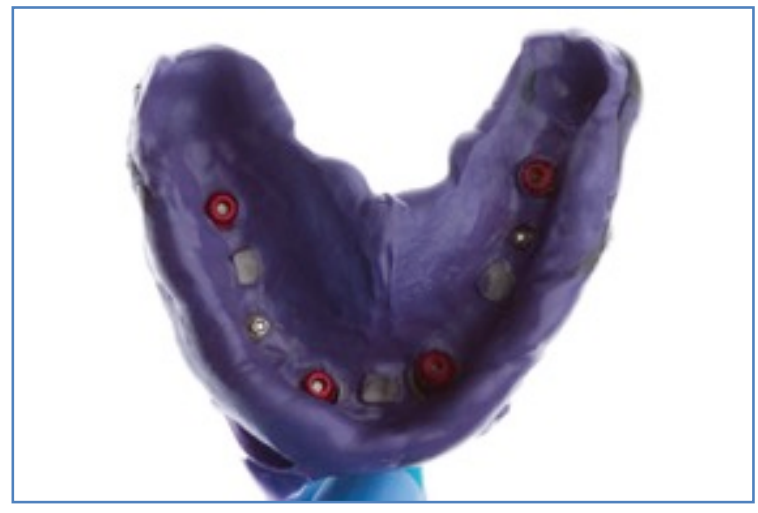

A)

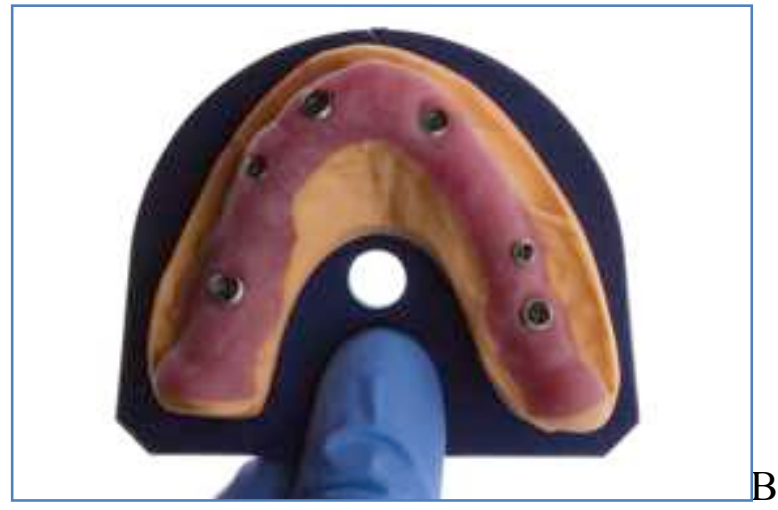

B) 
Fig. 10. Radiographic evaluation of metal-acrylic implant-borne prostheses. A, Maxillary right first molar and canine, B, Maxillary right central incisor, maxillary left central incisor, C, Maxillary left second premolar and first molar.

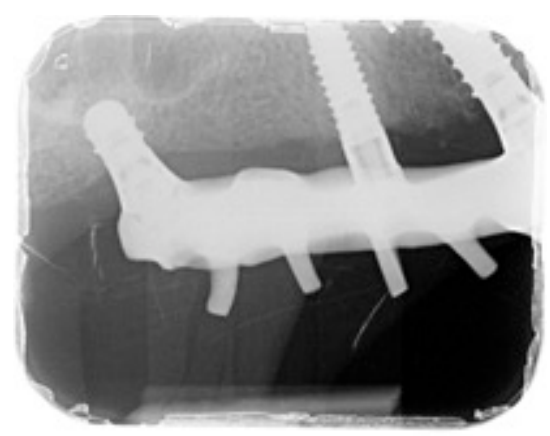

A)

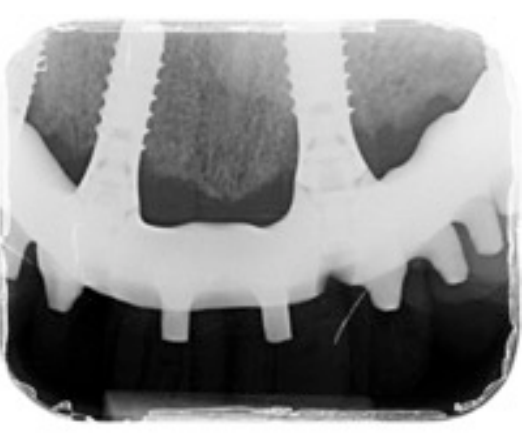

B)

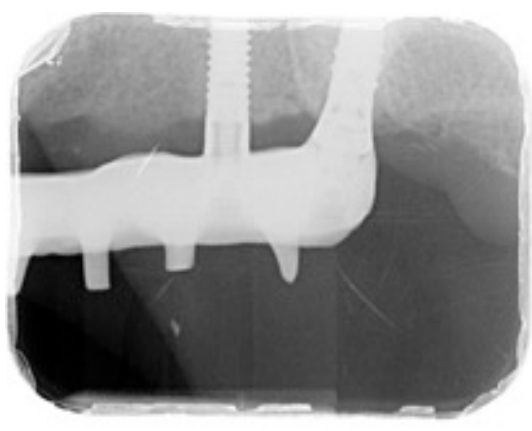

C) 